$\mathbb{T}$ periodica polytechnica

\author{
Chemical Engineering \\ $57 / 1-2(2013) 5355$ \\ doi: 10.3311/PPch. 2170 \\ http://periodicapolytechnica.org/ch \\ Creative Commons Attribution (1) \\ RESEARCH ARTICLE \\ Katalin Kupai / Gábor Hornyánszky / Lajos Novák \\ Received 2013-01-01, accepted 2013-03-04
}

\section{Investigation of the preparation of cycloalkanoindole derivative in ionic solvent}

\begin{abstract}
Optimization of the synthesis of carba analogs of physostigmine is described. Aza-Claisen-rearrangement, followed by aza-Alder-ene reaction of aniline derivatives gave the title product besides some byproduct. The effects of the amounts of catalyst, solvent, temperature and the method of heating were investigated.
\end{abstract}

\section{Keywords}

aza-Claisen rearrangement $\cdot$ aza-Alder-ene reaction $\cdot$ ionic solvent $\cdot$ optimization

\section{Katalin Kupai}

\section{Gábor Hornyánszky}

Department of Organic Chemistry and Technology, Budapest University of Technology and Economics, Gellért tér 4., Budapest, H-1111, Hungary

\section{Lajos Novák}

Department of Organic Chemistry and Technology, Budapest University of Technology and Economics, Gellért tér 4., Budapest, H-1111, Hungary e-mail: lnovak@mail.bme.hu
In recent years, we have published three papers on the convenient preparation of carba analogs of physostigmine [1]-[3]. Our method was based on the $\mathrm{BF}_{3} \cdot \mathrm{Et}_{2} \mathrm{O}$ catalyzed aza-Claisen rearrangement of (cycloalkylmethyl)benzenamine (Fig. 11, 1), followed by aza-Alder-ene reaction. Besides the wanted product (4) more or less by-product (3) was also formed by the migration of the carbon-carbon double bond.

In a continuation of our investigation on the synthesis, we tried to improve the yield of the wanted product (4) and minimize the formation of the byproduct (3). For this optimization we chose the rearrangement reaction of the unsubstituted benzeneamine $1(X=H, n=1)$.

Since the replacement of an organic solvent with ionic liquid had been found useful in some areas, we tried to use ionic fluid, too [4]-[7]. Furthermore, the extremely low vapor pressure of the ionic solvents characterized them as green solvent, allowing a wider range of applications. The reactions were then performed in methylimidazolium tetrafluoroborate at different concentrations and temperatures, and with thermal or microwaveassisted heating. The main advantage of this modification was the easy preparation of the product, namely it could be isolated by a simple extraction of the reaction mixture with organic solvent, and then directly analyzed by GC.

In the experiments $0.5 \mathrm{~g}$ of benzeneamine $(\mathbf{1}, X=H, n=1)$ was dissolved in $5 \mathrm{ml}$ or $2 \mathrm{ml}$ of methylimidazolium tetrafluoroborate and after adding the $\mathrm{BF}_{3} \cdot \mathrm{Et}_{2} \mathrm{O}$ catalyst ( 0.5 equiv.) portionwise, the mixture was heated to $175^{\circ} \mathrm{C}$ for $150 \mathrm{~min}$. Isolation of the product was carried out by extraction of the mixture with $\mathrm{CH}_{2} \mathrm{Cl}_{2}$. $\mathrm{GC}$ analysis of the extract showed that the concentrated solution gave preferential formation of the wanted product. In $5 \mathrm{ml}$ of ionic solvent we got a ratio of compounds 4 and $\mathbf{3}(X=H, n=1) 1: 1$ (18\% and 17\%, respectively). In 2 $\mathrm{ml}$ ionic solvent the result was the formation of $27 \%$ of wanted product and $14 \%$ of the by-product. (Besides these compounds, substantial amounts of unidentified tar were also formed).

We got better result when we added the catalyst $\left(\mathrm{BF}_{3} \cdot \mathrm{Et}_{2} \mathrm{O}\right)$ in one portion. Fig 2 shows the time course of the reaction. Here, the rather fast consumption of the starting material could be seen and we achieved $50 \%$ yield of compound $4(X=H, n=1)$. 
Fig. 1. Preparation of cycloalkano-indoles

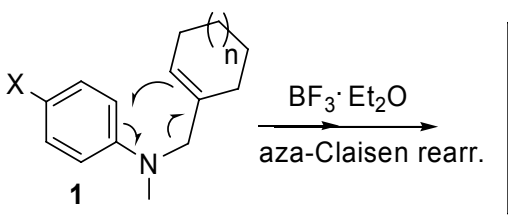

$\mathrm{X}=\mathrm{H}, \mathrm{OH}, \mathrm{OMe}, \mathrm{Cl}, \mathrm{Br}, \mathrm{I}$

$n=0-3$

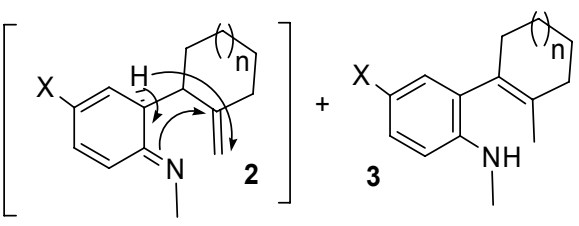

aza-Alder-ene reaction

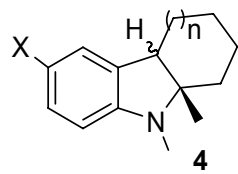

Fig. 2. Time course of preparation of compound 4 in methylimidazolium tetrafluoroborate

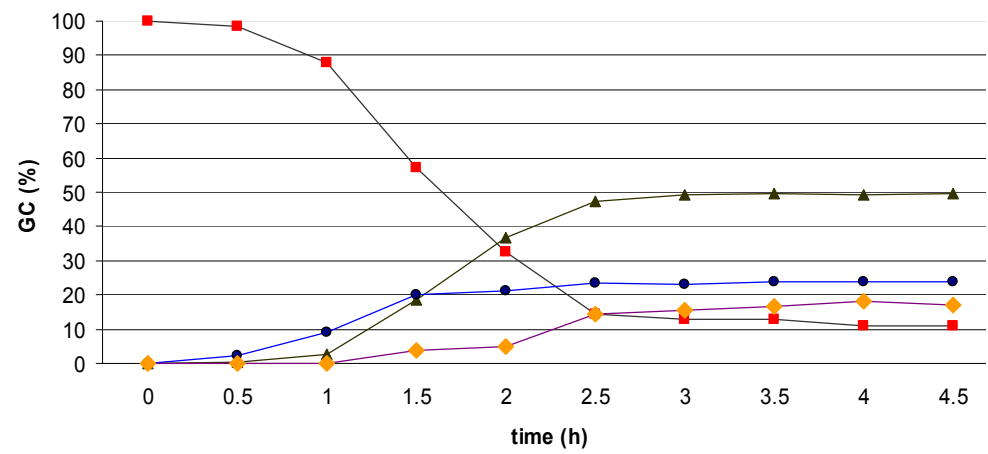

Compounds 1, 4, 3 and unidentified by-product are represented by squares $(\square)$, triangles $(\triangle)$, circles $(\circ)$, and diamonds $(\diamond)$

We also examined the effect of the reaction time on the formation of the wanted product. Table 1 shows the results.

Tab. 1. Effect of the temperature on the reaction $\mathbf{1} \rightarrow \mathbf{4}$.

\begin{tabular}{lccccc}
\hline Entry & $\begin{array}{c}\text { Temperature } \\
\left({ }^{\circ} \mathrm{C}\right)\end{array}$ & $\begin{array}{c}\text { Time } \\
(\mathrm{min})\end{array}$ & $\begin{array}{c}\text { Starting } \\
\text { compound }(\%)\end{array}$ & $\begin{array}{c}\text { Product } \\
(\%)\end{array}$ & $\begin{array}{c}\text { Byproduct } \\
(\mathbf{3}, \%)\end{array}$ \\
\hline 1 & 145 & 270 & 24 & 38 & 18 \\
2 & 165 & 180 & 27 & 36 & 20 \\
3 & 180 & 90 & 13 & 46 & 15 \\
4 & 190 & 10 & 0 & 68 & 4 \\
\hline
\end{tabular}

As can be seen, elevated temperature led to higher yield of the desired product (entries 1-3). We got the best yield of the product $(68 \%$, as a 2:1 mixture of cis and trans diastereomers) when we performed the reaction at $190{ }^{\circ} \mathrm{C}$ and added the catalyst in ionic solvent, and in one portion (entry 4). The ratio of diastereomers was determined by GC separation, followed by ${ }^{1} \mathrm{H}$ and ${ }^{13} \mathrm{C}$ NMR spectroscopy.

The reactions were also performed in microwave oven at elevated temperature $\left(170{ }^{\circ} \mathrm{C}\right)$. The ring-closure reaction took place in both sulfolane and methylimidazolium tetrafluoroborate, and we isolated compound 4 ( $X=H, n=1)$ in moderate yields (25\% and $27 \%$, respectively).

In conclusion, we have reported the optimization of the preparation of cycloalkanoindole derivative through thermal rearrangement of benzeneamine and got the title compound with moderate to good yields. Another advantage of this procedure was the use of a green solvent, methylimidazolium tetrafluorob- orate, which among various reaction solvents (decalin, tetralin and sulfolane) examined, gave the best yield of the desired product. These optimized conditions were subsequently employed to prepare compounds $4^{1}$

\section{References}

1 Király I, Hornyánszky G, Kolonits P, Novák L, Synthesis of cycloalkanoindoles, the carba analogs of physostigmine, Heterocycles, 75, (2008), 4356.

2 Kupai K, Bánóczi G, Hornyánszky G, Kolonits P, Novák L, A convenient method for the preparation of cyclohepta[b]indole derivatives, Cent. Eur. J. Chem., 10, (2012), 91-95.

3 Kupai K, Bánóczi G, Hornyánszky G, Kolonits P, Novák L, Facile synthesis of cycloalkanoindole derivatives by aza-Claisen rearrangements, Monatsch. Chem., 143, (2012), 1663-1669.

4 Barrer RM, The viscosity of pure liquids. II. Polymerized ionic melts, Trans. Faraday Soc., 39, (1943), 59-67.

5 Chum H.L., Koch VR, Miller LL, Osteryong RA, Electrochemical scruniy of organometallic iron complexis and hexamethylbenzene in a room temperature molten salt, J. Am. Chem. Soc., 97, (1975), 3264-.

6 Wilkes J, Levisky JA, Wilson RA, Hussey CL, Dialkylimidazolium chloroaluminate melts on new class of room temperature ionic liquid for electrochemistry, spectroscopy and synthesis, Inorg. Chem., 21, (1982), 12631264.

7 Earle M. J., Seddon KR, Ionic liquids. Green solvent for the future, Pure Appl. Chem., 72, (2000), 1391-1398.

\footnotetext{
${ }^{1}$ Generally we got $10 \%$ increase in yield. This will be the subject of a forthcoming publication.
} 